OPEN ACCESS

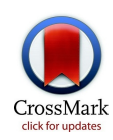

For numbered affiliations see end of article.

Correspondence to: J J Perry, Clinical Epidemiology Unit, F647, Ottawa Hospital, 1053, Carling Avenue, Ottawa, ON

Canada K1Y4E9 jperry@ohri.ca Additional material is published online only. To view please visit the journal online (http:// dx.doi.org/10.1136/BMJ.h568)

Cite this as: $B M J$ 2015;350:h568 doi: $10.1136 /$ bmj.h568

Accepted: 03 January 2015

\title{
Differentiation between traumatic tap and aneurysmal subarachnoid hemorrhage: prospective cohort study
}

\author{
Jeffrey J Perry, ${ }^{1}$ Bader Alyahya, ${ }^{1}$ Marco L A Sivilotti, ${ }^{2}$ Michael J Bullard, ${ }^{3}$ Marcel Émond, ${ }^{4}$ \\ Jane Sutherland, ${ }^{5}$ Andrew Worster, ${ }^{6}$ Corinne Hohl, ${ }^{7}$ Jacques S Lee, ${ }^{8}$ Mary A Eisenhauer, ${ }^{9}$ \\ Merril Pauls, ${ }^{10}$ Howard Lesiuk, ${ }^{11}$ George A Wells, ${ }^{12}$ lan G Stiell
}

\section{ABSTRACT}

OBJECTIVES

To describe the findings in cerebrospinal fluid from patients with acute headache that could distinguish subarachnoid hemorrhage from the effects of a traumatic lumbar puncture.

DESIGN

A substudy of a prospective multicenter cohort study. SETTING

12 Canadian academic emergency departments, from November 2000 to December 2009.

\section{PARTICIPANTS}

Alert patients aged over 15 with an acute non-traumatic headache who underwent lumbar puncture to rule out subarachnoid hemorrhage.

MAIN OUTCOME MEASURE

Aneurysmal subarachnoid hemorrhage requiring intervention or resulting in death.

RESULTS

Of the 1739 patients enrolled, 641 (36.9\%) had abnormal results on cerebrospinal fluid analysis with $>1 \times 10^{6} / \mathrm{L}$ red blood cells in the final tube of cerebrospinal fluid and/or xanthochromia in one or more tubes. There were $15(0.9 \%)$ patients with aneurysmal subarachnoid hemorrhage based on abnormal results of a lumbar puncture. The presence of fewer than $2000 \times 10^{6} / \mathrm{L}$ red blood cells in addition to no xanthochromia excluded the diagnosis of aneurysmal subarachnoid hemorrhage, with a sensitivity of $100 \%$ (95\% confidence interval $74.7 \%$ to $100 \%$ ) and specificity of $91.2 \%$ (88.6\% to $93.3 \%)$.

\section{CONCLUSION}

No xanthochromia and red blood cell count $<2000 \times 10^{6} / \mathrm{L}$ reasonably excludes the diagnosis of aneurysmal subarachnoid hemorrhage. Most patients with acute headache who meet this cut off will need no further investigations and aneurysmal subarachnoid hemorrhage can be excluded as a cause of their headache.

\section{Introduction}

Subarachnoid hemorrhage is a life threatening neurosurgical emergency. The estimated incidence is nine per

\section{WHAT IS ALREADY KNOWN ON THIS TOPIC}

It is often difficult to differentiate blood in cerebrospinal fluid from subarachnoid hemorrhage or as a result of traumatic tap

\section{WHAT THIS STUDY ADDS}

A red blood cell count of less than $2000 \times 10^{6} / \mathrm{L}$ and no xanthochromia reasonably rules out an aneurysmal subarachnoid hemorrhage
100000 person years. ${ }^{12}$ When a patient presents to the emergency department with sudden severe headache, traditional teaching is to perform computed tomography of the brain and, if the results are negative for subarachnoid hemorrhage, carry out a lumbar puncture to analyze the cerebrospinal fluid to exclude that diagnosis. ${ }^{3-6}$ The sensitivity of modern thin sliced computed tomography for subarachnoid hemorrhage is 100\% (95\% confidence interval $97 \%$ to $100 \%$ ) when it is performed within six hours of onset of the headache. If it is carried out after six hours, however, its sensitivity decreases to $85.7 \%$ (78.3\% to $90.6 \%) .^{7}$ Therefore, if the scan is performed more than six hours after headache onset and is negative for subarachnoid hemorrhage, the physician will typically perform lumbar puncture to rule it out.

Unfortunately, it can be difficult to differentiate whether the blood in the cerebrospinal fluid results from trauma related to the lumbar puncture itself or from a subarachnoid hemorrhage. A so called "traumatic tap" is estimated to occur in $10-30 \%$ of lumbar punctures, rendering the procedure non-diagnostic and often resulting in additional testing and diagnostic uncertainty. ${ }^{8}$ Several studies have attempted to find methods to differentiate traumatic tap from subarachnoid hemorrhage, but they have either been too small or had inconclusive results. ${ }^{9-11}$ Xanthochromia is considered to be pathognomonic for subarachnoid hemorrhage, but it is believed to take several hours to develop after headache onset. While xanthochromia can indicate subarachnoid blood, this blood might be caused by a perimesencephalic bleed or other non-aneurysmal bleed, which generally require only observation and have a good prognosis. ${ }^{12-14}$

We assessed the cerebrospinal fluid in prospectively enrolled patients with acute non-traumatic headache to determine if characteristics of cerebrospinal fluid can distinguish between traumatic tap and clinically relevant subarachnoid hemorrhage. ${ }^{15}$ We aimed to determine the optimal cut point for erythrocyte count in cerebrospinal fluid for clinically important subarachnoid hemorrhage and whether a combination of red blood cell count cut point and visual xanthochromia can reliably differentiate between traumatic tap and clinically relevant subarachnoid hemorrhage irrespective of the interval between the onset of headache and the lumbar puncture.

\section{Methods}

\section{Study design and setting}

This was a planned substudy from a prospective multicenter cohort study, designed to derive and validate the Ottawa SAH (subarachnoid hemorrhage) rule $(n=4141)$. 
It was conducted between November 2000 and December 2009. Patients were enrolled from 12 Canadian academic emergency departments. Study sites had a mean of 52000 visits annually and a mean of 445 inpatient beds.

\section{Study population}

We enrolled alert patients aged over 15 who presented to the emergency department with acute non-traumatic headache and underwent lumbar puncture to rule out subarachnoid hemorrhage. "Alert patients" were defined as having a score on the Glasgow coma scale of 15 (that is, alert and oriented), "Non-traumatic" was defined as no fall or direct head trauma in the seven days before presentation. "Acute headache" was defined as one that reached maximum intensity within an hour of onset. Patients were excluded if they presented more than 14 days after the onset of headache; had recurrent headaches (three or more headaches of similar character and intensity as the presenting headache over a period of more than six months); were transferred from another hospital with a confirmed subarachnoid hemorrhage; and had focal neurological deficits, papilledema, or a history of subarachnoid hemorrhage, aneurysm, ventricular shunt, or brain neoplasm. Computed tomography was performed at the discretion of the treating physician. Lumbar puncture was also performed at the discretion of the treating physician, who was aware of the clinical decision rule study but was advised not to alter usual care because of the study. While many physicians order a lumbar puncture after normal results on computed tomography, some physicians follow the strategy of lumbar puncture first. ${ }^{16}$ The decision of whether a lumbar puncture was warranted and when it was performed was at the discretion of the treating physician.

\section{Data collection}

Treating physicians recorded clinical histories and examination findings, and research registered nurses collected additional reliably recorded data (such as demographics and initial vital signs). For this substudy, study physicians recorded additional laboratory data including the presence of xanthochromia in the cerebrospinal fluid, red and white blood cell counts in the first and last tubes of cerebrospinal fluid collected, and glucose and protein concentrations in cerebrospinal fluid. The laboratory results were reported according to the routine laboratory analysis at each site, with red cell counts $>1 \times 10^{6} / \mathrm{L}$ (equivalent to $\mathrm{n} / \mathrm{mm}^{3}$ or $\mathrm{n} / \mu \mathrm{L}$ ) in the final tested tube of cerebrospinal fluid or xanthochromia in any tube of cerebrospinal fluid collected considered abnormal. For the purpose of our study, we considered as normal cerebrospinal fluid samples that had only increased white blood cell counts but normal red blood cell counts and no xanthochromia.

\section{Outcome measures}

Our outcome was aneurysmal subarachnoid hemorrhage. Patients were deemed to have aneurysmal subarachnoid hemorrhage if they had blood in the subarachnoid space on plain computed tomography of the brain or xanthochromia on examination of cerebrospinal fluid or red blood cells in the final tube of cerebrospinal fluid and they had an aneurysm shown with cerebral angiography (digital subtraction, magnetic resonance, or computed tomography) requiring any neurovascular intervention or resulting in death. We did not include non-aneurysmal subarachnoid hemorrhages in our outcome definition.

Experienced radiologists or neuroradiologists, who were unaware of our study, assessed computed tomograms as per normal practice. We utilized their final report to determine the presence of subarachnoid blood on the scan. The assessment of cerebrospinal fluid was done at the site hospital laboratories following their local protocols. Five of the six sites utilized visual xanthochromia, with one site using spectrophotometry to determine xanthochromia.

\section{Proxy outcome measure}

As this was an observational study, we could not alter current practice. Therefore patients discharged without having both computed tomography imaging and a normal result on lumbar puncture were assessed with our proxy outcome assessment tool. This assessment tool included a structured telephone interview one month and six months after assessment in the emergency department as well as a review of medical records to identify any patients who experienced a subsequent subarachnoid hemorrhage. The telephone call assessed repeat physician visits, change in diagnosis, and subsequent testing with computed tomography, lumbar puncture, angiography, or magnetic resonance imaging. We internally validated our follow-up tool to identify subarachnoid hemorrhage during our previous phase I derivation study. ${ }^{18}$ When available, patients without telephone follow-up or subsequent hospital encounters at the enrolling sites were further checked against the provincial coroner's office to identify any deaths compatible with subarachnoid hemorrhage. Any patients found to have a subsequent aneurysmal subarachnoid hemorrhage within six months were classified as having a positive event for the enrolling visit, with all others being classified as negative.

\section{Analysis}

In addition to descriptive analyses, we used univariate analysis two sided Student $t$ test for continuous variables, Mann-Whitney U test for non-parametric data, and $x^{2}$ test for categorical data. We chose performance thresholds to optimally exclude clinically important subarachnoid hemorrhaged in lumbar punctures with abnormal results by creating high and low risk criteria. The sample size was based on all available data from the derivation and validation phases of the Ottawa subarachnoid hemorrhage rule..$^{17} 18$

\section{Results}

From the 4141 patients (including 146 with aneurysmal subarachnoid hemorrhage) enrolled in our derivation and validation clinical decision rule study cohorts, the 1739 patients who underwent lumbar puncture were 
Fig 1 | Identification and flow of patients with acute non-traumatic headache

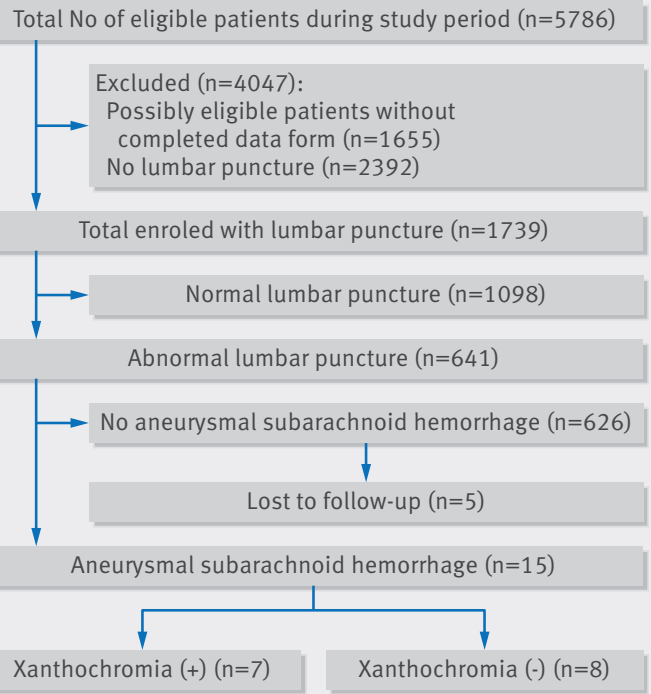

enrolled in this substudy. In 641 patients (36.9\%) cerebrospinal fluid was found to contain red blood cells $\left(>1 \times 10^{6} / \mathrm{L}\right)$ in the final tube or xanthochromia was seen in any tube (fig 1). Aneurysmal subarachnoid hemorrhage was identified in 15 patients undergoing lumbar puncture. There were 1652 patients with normal results on computed tomography and 10 with visible subarachnoid hemorrhage, unrecognized by the treating emergency physician. There were 77 (4.4\%) patients who did not undergo computed tomography, none of whom was diagnosed with subarachnoid hemorrhage.

Table 1 shows the baseline characteristics of patients enrolled in our derivation and validation cohort study. The mean age was 43.8. There were slightly more women $(2497,60.4 \%)$ than men. The mean headache severity was 8.7 (scale from 0 to 10), and the median time from onset of headache to peak pain was 60 seconds (interquartile range 1-600). For the 1739 (42.1\%) patients who had a lumbar puncture and were enrolled in this substudy, the median time from onset of headache to lumbar puncture was 17 hours. Of the 15 cases of subarachnoid hemorrhage identified by lumbar puncture, seven were identified with xanthochromia (red blood cell counts $32-299365 \times 10^{6} / \mathrm{L}$ ), the others being identified from an abnormal erythrocyte count in the cerebrospinal fluid (range 9750-600 000 $\times 10^{6} / \mathrm{L}$ ). Table 1 also stratifies the patients with normal versus abnormal findings on lumbar puncture. Other than the presence of red blood cells and the diagnosis of subarachnoid hemorrhage, these two groups of patients were similar.

Overall, 641 (36.9\%) of the lumbar punctures in our cohort yielded abnormal results. Figure 2 shows the red blood cell counts associated with these abnormal results. In most patients the red blood cell counts were relatively low: $476(74.3 \%)$ had counts of $\leq 100 \times 10^{6} / \mathrm{L}$, $94(14.8 \%)$ had counts of $101-1000 \times 10^{6} / \mathrm{L}$, and 71 $(10.6 \%)$ had counts of $>1000 \times 10^{6} / \mathrm{L}$.

Table 2 lists the characteristics of patients with abnormal results on lumbar puncture according to presence or absence of subarachnoid hemorrhage. The median duration between onset of headache and lumbar puncture was not significantly different among those with and without aneurysmal subarachnoid hemorrhage (30.0 $v 18.7$ hours, $\mathrm{P}=0.13$ ). The median red blood cell count in the last tube was significantly higher among the patients with aneurysmal subarachnoid hemorrhage than in those without $\left(28741 \times 10^{6} / \mathrm{L} v\right.$ $20 \times 10^{6} / \mathrm{L}$, respectively, $\left.\mathrm{P}<0.001\right)$. There was a higher protein concentration in the cerebrospinal fluid of patients with subarachnoid hemorrhage than in those without $(0.56 \mathrm{~g} / \mathrm{L} v 0.40 \mathrm{~g} / \mathrm{L}, \mathrm{P}=0.033)$. Characteristics of the 15 patients with aneurysmal subarachnoid hemorrhage are listed in the appendix.

We assessed the optimal cut point using a receiver operator characteristic curve (fig 3). We propose a red blood cell count in the final tube of cerebrospinal fluid of $\leq 2450 \times 10^{6} / \mathrm{L}$, which we rounded down to $<2000 \times 10^{6} / \mathrm{L}$ to provide a value that is more practical for clinicians to remember. This cut point has a sensitivity of $93.3 \%$ (95\% confidence interval $66.0 \%$ to $99.7 \%$ ) and specificity of $92.8 \%$ (90.5\% to $94.6 \%$ ) for aneurysmal subarachnoid hemorrhage. In our study

Table 1 | Baseline characteristics of 1739 patients with acute non-traumatic headache attending emergency department who underwent lumbar puncture to rule out subarachnoid hemorrhage. Figures are numbers (percentage) of patient unless otherwise specified

\begin{tabular}{|c|c|c|c|}
\hline & \multicolumn{2}{|c|}{ Underwent lumbar puncture } & \multirow{2}{*}{$\begin{array}{l}\text { All patients in } \\
\text { derivation } \\
\text { and validation } \\
\text { cohorts } \\
(n=4131)\end{array}$} \\
\hline & $\begin{array}{l}\text { Normal result } \\
(n=1098)\end{array}$ & $\begin{array}{l}\text { Abnormal } \\
\text { result }(n=641)\end{array}$ & \\
\hline Mean (SD) age (years) & $41.6(15.5)$ & $45.1(16.2)$ & $43.8(17.1)$ \\
\hline Women & $625(56.9)$ & $369(57.6)$ & $2497(60.4)$ \\
\hline Vomiting & $307(28.0)$ & $196(30.6)$ & $1174(28.6)$ \\
\hline Neck pain or stiffness & $399(36.3)$ & $273(42.6)$ & $1393(33.7)$ \\
\hline Median (IQR) time of headache onset to peak (seconds) & $10(1-180)$ & $10(1-120)$ & $60(1-600)$ \\
\hline Computed tomography performed & $1079(98.3)$ & $622(97.0)$ & $3374(81.7)$ \\
\hline
\end{tabular}


Fig 2 | Distribution of abnormal red cell counts in cerebrospinal fluid in patients with abnormal results on lumbar puncture $(n=641)$

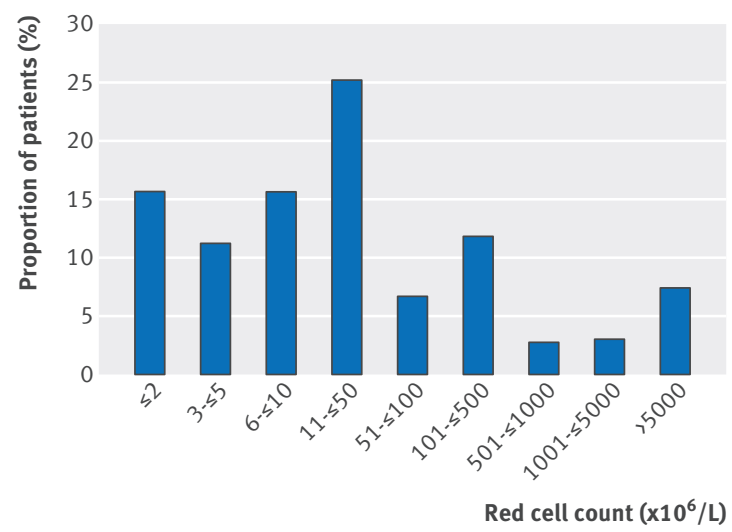

the sensitivity of visual xanthochromia for diagnosis was $46.7 \%(22.3 \%$ to $72.6 \%)$ and the specificity was $97.3 \%$ (95.6\% to $98.4 \%)$.

Figure 4 shows the classification performance of threshold used to diagnose subarachnoid haemorrhage in those with abnormal lumbar puncture. We utilized the combined definition for a low risk of subarachnoid hemorrhage as red blood cells $<2000 \times 10^{6} / \mathrm{L}$ in cerebrospinal fluid and no xanthochromia and high risk as $\geq 2000 \times 10^{6}$ red blood cells/L or xanthochromia. The sensitivity of this risk threshold for aneurysmal subarachnoid hemorrhage was 100\% (95\% confidence interval $74.7 \%$ to $100.0 \%$ ); the specificity was $91.2 \%$ (88.6\% to $93.3 \%$ ); and the positive likelihood ratio was 11.4 (8.8\% to 14.6$)$. The negative likelihood ratio was 0 (95\% confidence interval was undefined).

\section{Discussion}

Lumbar puncture remains an essential investigation for the diagnosis of subarachnoid hemorrhage as the sensitivity of computed tomography degrades with delays to presentation. In a large cohort of such we have shown that cerebrospinal fluid with no xanthochromia and less than $2000 \times 10^{6} / \mathrm{L}$ red blood cells safely excludes this diagnosis.

A delay in the diagnosis of subarachnoid hemorrhage can have devastating consequences. Several studies have reported misdiagnosis on the first visit to a physician. In one population based study, subarachnoid hemorrhage was misdiagnosed in up $5.4 \%$ of patients at the first emergency department visit. These patients pre- sented to an emergency department with headache and returned within seven days with subarachnoid hemorrhage. Subarachnoid hemorrhage were more commonly misdiagnosed in smaller more rural sites. ${ }^{19}$ Delay in diagnosis has been associated with increased morbidity and mortality. ${ }^{20}$ Hence timely investigations, including a lumbar puncture when indicated, are needed for patients at risk for subarachnoid hemorrhage.

Given that nearly $37 \%$ of the lumbar punctures in our cohort yielded abnormal results, differentiation between traumatic tap and true subarachnoid hemorrhage is needed in a third of the lumbar punctures performed. While some might consider this differentiation to be relatively easy in over half of these cases because the number of red blood cells is low (such as $<100 \times 10^{6} / \mathrm{L}$ ), even these low numbers give many, often less experienced physicians, a great deal of anxiety especially in the absence of clear evidence to the contrary.

We did identify that 10 of the 15 patients in this substudy with aneurysmal subarachnoid hemorrhage had blood visible on computed tomography which was presumably not identified prior to the lumbar puncture. The final interpretation of off-hour imaging results by an attending radiologist was often delayed until the next working day at participating sites, and small amounts of subarachnoid blood can be difficult for other physicians to appreciate. Timely interpretation of emergency imaging by an experienced radiologist could shorten delay to treatment and minimize the number of lumbar punctures ultimately deemed unnecessary, although this scenario is uncommon and the overall rate of lumbar puncture would not change appreciably.

We found a significantly higher concentration of protein in cerebrospinal fluid in patients with subarachnoid hemorrhage than in those without. The clinical relevance of $0.56 \mathrm{~g} / \mathrm{L}$ compared with $0.40 \mathrm{~g} / \mathrm{L}$, however, is not reassuring. We also found that the median time from headache to lumbar puncture was 17 hours. Interestingly, the median time to lumbar puncture was longer in patients with abnormal results on lumbar puncture compared with those with normal results. While the median time in the group with subarachnoid hemorrhage was 30 hours, this was not significantly different from other patients with abnormal lumbar puncture results, probably because of the small number of cases. The results, however, likely represent a combination of

Table 2 | Characteristics of 641 patients with acute non-traumatic headache with abnormal results on lumbar puncture. Figures are numbers (percentage) of patient unless otherwise specified

\begin{tabular}{|c|c|c|c|}
\hline & $\begin{array}{l}\text { Aneurysmal } \\
\text { subarachnoid } \\
\text { hemorrhage }(n=15)\end{array}$ & $\begin{array}{l}\text { No subarachnoid } \\
\text { hemorrhage } \\
(n=626)\end{array}$ & P value \\
\hline Mean (SD) age (years) & $49.6(14.2)$ & $45.0(16.2)$ & 0.28 \\
\hline Women & $10(66.7)$ & $359(57.3)$ & 0.47 \\
\hline Median (IQR) time of headache onset to peak (seconds) & $38(3-210)$ & $10(1-120)$ & 0.64 \\
\hline Median (IQR) time from headache onset to lumbar puncture (hours) & $30.0(14.0-120)$ & $18.7(9.0-50.8)$ & 0.13 \\
\hline Positive xanthochromia & 46.6 & 2.6 & $<0.001$ \\
\hline Median (IQR) red blood cells count in last tube $\left(\times 10^{6} / \mathrm{L}\right)$ & $28741(12468-74789)$ & $20(7-110)$ & $<0.001$ \\
\hline Median (IQR) cerebrospinal fluid protein concentration (g/L) & $0.56(0.38-0.92)$ & $0.40(0.31-0.54)$ & 0.033 \\
\hline Angiography rate & 15 (100) & $404(64.5)$ & 0.004 \\
\hline
\end{tabular}


Fig 3 | Receiver operator characteristic curve for subarachnoid hemorrhage by red blood cell count. Point labels are values of RBCVALUREVISED.

Approximate area under curve $=0.948$

Fig 4 | Classification performance of threshold used to diagnose subarachnoid hemorrhage in patients with acute headache and abnormal lumbar puncture results

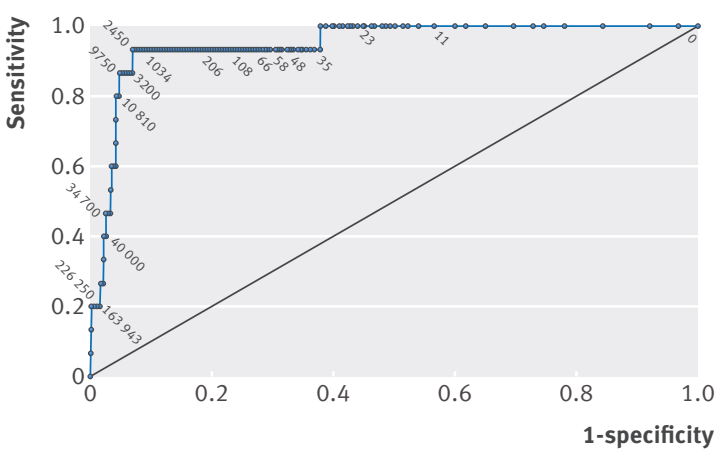

\begin{tabular}{|c|c|c|}
\hline & $\begin{array}{c}\text { Positive for } \\
\text { subarachnoid } \\
\text { emorrhage }(n=15)\end{array}$ & $\begin{array}{c}\text { Negative for } \\
\text { subarachnoid } \\
\text { hemorrhage }(n=626)\end{array}$ \\
\hline \multicolumn{3}{|l|}{ Classification: } \\
\hline High risk & 15 & 55 \\
\hline Low risk* & 0 & 571 \\
\hline Sensitivity \% $(95 \% \mathrm{Cl})$ & \multicolumn{2}{|c|}{$100.0(74.7$ to 100$)$} \\
\hline Specificity \% $(95 \% \mathrm{Cl})$ & \multicolumn{2}{|c|}{91.2 (88.6 to 93.3$)$} \\
\hline Positive likelihood ratio \% (95\% Cl) & \multicolumn{2}{|c|}{$11.4(8.8$ to 14.6$)$} \\
\hline Negative likelihood ratio \% $(95 \% \mathrm{Cl})$ & \multicolumn{2}{|c|}{$0(N A) \dagger$} \\
\hline Positive predictive value $\%(95 \% \mathrm{Cl})$ & \multicolumn{2}{|c|}{21.4 (12.9 to 33.2$)$} \\
\hline Negative predictive value $\%(95 \% \mathrm{Cl})$ & \multicolumn{2}{|c|}{$100.0(99.2$ to 100.0$)$} \\
\hline
\end{tabular}

clinicians' reliance on early computed tomography to exclude subarachnoid hemorrhage, the time it takes for patients to have a lumbar puncture performed in busy emergency departments, and some clinicians waiting for 12 hours as recommended in traditional teaching. There were no criteria requiring clinicians to wait for 12 hours after onset of headache at any of our 12 study sites. As such, nearly $37 \%$ of the lumbar punctures with abnormal results and nearly $39 \%$ of all lumbar punctures were done within 12 hours after onset of headache. The literature suggesting this timeline was a study assessing for xanthochromia using a specific spectrophotometer assessment on patients with known subarachnoid hemorrhage. ${ }^{21}$ There is no evidence that we are aware of that has assessed the usefulness of waiting for 12 hours in patients with undifferentiated headache with or without spectrophotometry.

Although select definitions of spectrophotometry might have higher sensitivity for xanthochromia, they are associated with high rates of false positive results. ${ }^{21-24}$ In our study we primarily used visual xanthochromia (at five of six sites), as this is the method utilized in about $97 \%$ of North American hospitals. ${ }^{25}$ In our study the sensitivity of xanthochromia to diagnose aneurysmal subarachnoid hemorrhage was $46.6 \%$ ( $95 \%$ confidence interval $22.3 \%$ to $72.6 \%$ ). The sensitivity of isolated visual xanthochromia in our study was consistent with previous retrospective studies that ranged between $47 \%$ and $93 \% .{ }^{21} 2627$ While some studies suggest that spectrophotometry is superior to visual xanthochromia assessment, these studies did not utilize a combination of red blood cell count or xanthochromia. When this composite assessment is used, the sensitivity for subarachnoid hemorrhage is $100 \% .{ }^{22}$ Furthermore, a recent meta-analysis comparing visual and xanthochromia defined with spectrophotometry found the sensitivities for subarachnoid hemorrhage to be $83 \%$ (59\% to $96 \%$ ) and $87 \%$ ( $71 \%$ to $96 \%$ ), respectively. The specificities were $96 \%$ ( $93 \%$ to $97 \%$ ) and $86 \%$ ( $84 \%$ to $88 \%$ ), respectively. ${ }^{28}$ Further, the combination of negative results on computed tomography with normal results on cerebrospinal fluid analysis (that is, no visual xanthochromia and no red blood cells) has been previously shown to rule out subarachnoid hemorrhage..$^{29}$ Hence, isolated visual xanthochromia is less sensitive but more specific than spectrophotometry defined xanthochromia, but the use of both red blood cell counts in cerebrospinal fluid and visual xanthochromia seems to be most sensitive. Our finding of a reliable cut point now increases the specificity while maintaining a high specificity when both visual xanthochromia and red blood cell count in cerebrospinal fluid are used to identify patients at high risk for subarachnoid hemorrhage.

Previous attempts to differentiate blood in cerebrospinal fluid from a traumatic procedure versus a subarachnoid hemorrhage have included inspection for the presence of xanthochromia, the change in red blood cells number between the first and last tube of collected cerebrospinal fluid, cerebrospinal fluid opening pressure, cerebrospinal fluid D-dimer, bilirubin, and ferritin.9 3031 None resulted in a suitable method of differentiation, with most of the studies being retrospective with small numbers of patients. While our study had relatively few positive cases of aneurysmal subarachnoid hemorrhage, our study included a large number of patients with undifferentiated headache.

The most promising previous study was a retrospective study with 594 patients who had lumbar puncture for the complaint of headache, 11 of whom received a diagnosis of subarachnoid hemorrhage and $142 \mathrm{had}$ a traumatic tap. This study found that red blood cell counts of $\leq 500 \times 10^{6} / \mathrm{L}$ in the fourth tube had a $100 \%$ negative predictive value for subarachnoid hemorrhage. ${ }^{8}$ The same study found that clearance of red blood cells from the first to the fourth tube of at least $70 \%$ also excluded the diagnosis of subarachnoid hemorrhage. This study was limited by small numbers overall, and few patients had subarachnoid hemorrhage. Our findings, however, were consistent with these results, with a high sensitivity for red blood cell counts $<2000 \times 10^{6} / \mathrm{L}$. The cases of aneurysmal subarachnoid hemorrhage missed by this threshold were identified with additional assessment for visual xanthochromia. The method of assessing a drop in red blood cell counts was discounted by another small retrospective study; in two patients with subarachnoid hemorrhage they found a $25 \%$ reduction of red blood cells between the first and fourth tube of cerebrospinal fluid collected. ${ }^{10}$ While it might be feasible to rule in a traumatic tap, it must be remembered that a traumatic tap and a subarachnoid hemorrhage can coexist as they are independent conditions. Given this knowledge, we did not attempt to assess for a safe drop in red blood cell counts from the first to final tube.

Another study assessed 280 patients retrospectively based on the presence of abnormal results on lumbar 
puncture and neurovascular imaging within two weeks. That study found that no patients with $<100 \times 10^{6} / \mathrm{L}$ had a subarachnoid hemorrhage. This is mostly consistent with our study results. For values of $100-10000 \times 10^{6} / \mathrm{L}$, it is unclear how sensitive a cut point of $2000 \times 10^{6} / \mathrm{L}$ would be for aneurysmal subarachnoid hemorrhage in their series. ${ }^{2} 32$

\section{Strengths and limitations}

To our knowledge, this is the largest prospectively conducted study that differentiates traumatic tap from subarachnoid hemorrhage in patients with undifferentiated headache. We included patients from 12 emergency departments and used rigorous follow-up protocols to optimize the quality of this study. This is the first prospective study to propose a threshold that combines a cut off number of red blood cells in cerebrospinal fluid and negative xanthochromia to exclude the diagnosis of aneurysmal subarachnoid hemorrhage.

Some physicians did not collect, or the laboratory did not process, more than one tube of cerebrospinal fluid. In addition, a few tubes were clearly misnumbered with much higher red blood cell counts in the final tubes than in the first tubes. To overcome this issue, we considered the tube with the lowest erythrocyte count when assessing cut points for red blood cell counts. In addition we did not assess for adverse events related to the lumber puncture (for instance, post-lumbar puncture headache, infection, or bleeding).

We assessed xanthochromia and red blood cell counts, which were also part of the definition of aneurysmal subarachnoid hemorrhage. These tests alone, however, did not fulfill our main outcome measure definition, which also required an aneurysm to be present and for the patient to either undergo a neurosurgical intervention or die.

Our proxy outcome of assessing patients without both normal results on computed tomography and lumbar puncture entailed a chart review and telephone follow-up. Utilizing this process we missed only five patients. These patients were classified as having no subarachnoid hemorrhage as they did not have any subsequent encounters at the local neurosurgical sites and were not reported to the local coroner as having died. It is possible, albeit unlikely, that we could have missed up to five cases of subarachnoid hemorrhage by relying on this proxy outcome tool.

While the point estimate for the sensitivity of our high risk criteria was $100 \%$, the $95 \%$ confidence intervals were wide. These wide confidence intervals highlight just how rarely patients have a diagnosis of subarachnoid hemorrhage after lumbar puncture. In nearly all patients in our cohort the diagnosis was made with computed tomography. Only 15 received a diagnosis after lumbar puncture, and almost half of these were identified by xanthochromia. Hence, only eight cases were identified over a 10 year period at 12 sites, where $71.4 \%$ of eligible patients were enrolled. We therefore believe that these high risk criteria are pragmatic and will help physicians to identify when they need to be concerned about subarachnoid hemorrhage. Our conclusions, however, are based on only eight patients. While we believe that our conclusions are appropriate for most patients (about 90\%), those with a high pretest probability might need further investigation with cerebral angiography if they have an abnormal results on cerebrospinal fluid analysis that are classified as low risk. Our study was the first to use a combination of red blood cells and xanthochromia to differentiate subarachnoid hemorrhage from a traumatic tap.

\section{Clinical implications}

The ability to differentiate traumatic tap from subarachnoid hemorrhage based on the analysis of cerebrospinal fluid samples will help emergency physicians to make appropriate and timely disposition of patients with suspected subarachnoid hemorrhage. This will reduce the risk of inappropriate discharge of patients with a life threatening condition and eliminate the cost and potential morbidity (such as unnecessary surgery from an incidental aneurysm, nephrotoxicity, or allergic reaction) of unnecessary cerebral angiography or hospital admissions. We recommend that physicians utilize our high and low risk cut points to interpret results of lumbar puncture when assessing patients with acute headache for possible subarachnoid hemorrhage. We also recommend having an experienced radiologist assess computed tomograms when feasible before patients undergo a lumbar puncture.

\section{Conclusion}

No xanthochromia and red blood cell count $<2000 \times 10^{6} / \mathrm{L}$ reasonably exclude the diagnosis of aneurysmal subarachnoid hemorrhage. Most patients with acute headache who meet this cut off will require no further investigations, and aneurysmal subarachnoid hemorrhage can reasonably be excluded as a cause of their headache.

\section{AUTHOR AFFILIATIONS}

'Department of Emergency Medicine, University of Ottawa, Ottawa Hospital Research Institute, Ottawa Hospital 1053 Carling Avenue Room F647, Ottawa, ON, Canada, K1Y 4E9

2University of Ottawa, Department of Emergency Medicine, Ottawa, ON, Canada

${ }^{3}$ Department of Emergency Medicine, University of Alberta, Edmonton, AB, Canada

${ }^{4}$ Hopital de l'Enfant-Jesus, Department of Emergency Medicine, Faculty of Medicine, Quebec City, QC, Canada G1J 1 Z4

${ }^{5}$ Clinical Epidemiology Program, Ottawa Hospital Research Institute, Ottawa, ON, Canada

${ }^{6}$ Department of Emergency Medicine, McMaster University, Hamilton, ON, Canada

7Department of Emergency Medicine, University of British Columbia, Vancouver, BC, Canada

${ }^{8}$ Division of Emergency Medicine, University of Toronto, Toronto, ON, Canada

${ }^{9}$ Division of Emergency Medicine, University of Western Ontario, London, ON, Canada

${ }^{10}$ Department of Emergency Medicine, University of Manitoba, Winnipeg, MB, Canada

${ }^{11}$ Division of Neurosurgery, University of Ottawa, Ottawa, ON, Canada

${ }^{12}$ Department of Epidemiology and Community Medicine, University of Ottawa, Ottawa Hospital Research Institute, Ottawa, ON, Canada

We thank the hundreds of physicians who completed our data collection forms and the emergency department nurses and clerks at the 12 study 
sites for their cooperation with the study. We also thank Albert E Lauwers, deputy coroner, and the Office of the Coroner of Ontario for their assistance in verifying outcomes and the following research personnel at the study hospitals: Vancouver General Hospital, Vancouver, BC (Jan Buchanan, Lauren Stewart); London Health Sciences Centre, London, ON (Evelyn Gilkinson); Ottawa Hospital-Civic Campus and General Campuses, Ottawa, ON (Erica Battram, Juanita Wilzer, Nicole Fortin, Renée Labreche); University of Alberta, Edmonton, AL (Harris Lari, Leslie Saunders, Ginny Willis, Sandy Sandilands); Sunnybrook Health Sciences Centre, Toronto, ON (Deborah Wright, Johanna Pak); Kingston General Hospital, Kingston, ON (Kathy Bowes, Julie Richard, Deborah Crosby, Jane Reid); Hôpital de L'Enfant-Jésus, Quebec City, QB (Patricia Chabot); Hamilton Health Sciences Centre, Hamilton, ON (Christina Brean); Lethbridge Regional Hospital, Lethbridge, AB (Marlene Myles); Winnipeg Health Sciences Centre, Winnipeg, MB (Irene Osinchuk). We also thank our colleagues at the Ottawa Hospital Research Institute (Sarai Cohn-Kalter, Malaika Mvungi, Sheryl Domingo, My-Linh Tran, Irene Harris, and Angela Marcantonio) for their assistance with this project.

This work was presented at the Society for Academic Emergency Medicine (SAEM) Atlanta, GA, May 2013, and at the Canadian Association of Emergency Physicians (CAEP) Annual Scientific Meeting, Vancouver, BC, Canada, June 2013.

Contributors: JJP conceived the idea and prepared the manuscript with BA. JS coordinated the study, collected data, and contributed to the writing of the manuscript. GAW provided considerable statistical assistance and revised the manuscript. MLAS, MJB, ME, AW, CH, JSL, MAÉ, MP, HL, and IGS assisted with study design and revised the manuscript. JPP is guarantor.

Funding: This research was funded by the Canadian Institutes of Health Research (grants: 67107, 153742), the Ontario Ministry of Health and Long Term Care, and the physicians of Ontario through the Physician's Services Incorporated Foundation (01-39). JPP is supported by a Canadian Institutes of Health Research New Investigator Award and was previously supported as a career scientist by the Ontario Ministry of Health. IGS is a distinguished professor and university health research chair, University of Ottawa. $\mathrm{CH}$ is supported by a Canadian Institutes of Health Research New Investigator Award and was previously supported by a Mentored Clinician Scientist Award from the Vancouver Coastal Health Research Institute.

Competing Interests: All authors have completed the ICMJE uniform disclosure form at www.icmje.org/coi disclosure.pdf and declare: no support from any organization for the submitted work; no financial relationships with any organizations that might have an interest in the submitted work in the previous three years; no other relationships or activities that could appear to have influenced the submitted work. Ethical approval: The study was approved at each of the 12 participating hospital research ethics boards, with a waiver of informed consent for this minimal risk, observational study. The Ottawa Health Science Network research ethics board was the oversight REB, and the corresponding protocol number issued by the board is $2009316-01 \mathrm{H}$

Transparency: The lead author, JPP affirms that the manuscript is an honest, accurate, and transparent account of the study being reported; that no important aspects of the study have been omitted; and that any discrepancies from the study as planned have been explained. Data sharing: No additional data available.

This is an Open Access article distributed in accordance with the Creative Commons Attribution Non Commercial (CC BY-NC 4.0) license, which permits others to distribute, remix, adapt, build upon this work non-commercially, and license their derivative works on different terms, provided the original work is properly cited and the use is noncommercial. See: http://creativecommons.org/licenses/by-nc/4.0/.

1 De Rooij NK, Linn FH, van der Plas JA, Algra A, Rinkel GJ. Incidence of subarachnoid haemorrhage: a systematic review with emphasis on region, age, gender and time trends. I Neurol Neurosurg Psychiatry 2007;78:1365-72.

2 Thomas LE, Czuczman AD, Boulanger AB, Peak DA, Miller ES, Brown $D F$, et al. Low risk for subsequent subarachnoid hemorrhage for emergency department patients with headache, bloody cerebrospinal fluid, and negative findings on cerebrovascular imaging. I Neurosurg 2014;121:24-31.

3 Edlow JA, Caplan LR. Avoiding pitfalls in the diagnosis of subarachnoid hemorrhage. N Engl/ Med 2000;342:29-36.

4 Byyny RL, Mower WR, Shum N, Gabayan GZ, Fang S, Baraff LJ. Sensitivity of noncontrast cranial computed tomography for the emergency department diagnosis of subarachnoid hemorrhage. Ann Emerg Med 2008;51:697-703.

5 Edlow JA, Panagos PD, Godwin SA, Thomas TL, Decker WW. Clinical policy: critical issues in the evaluation and management of adult patients presenting to the emergency department with acute headache. Ann Emerg Med 2008;52:407-36.
6 Schievink WI. Intracranial aneurysms. N Engl / Med 1997;336:28-40.

7 Perry JJ, Stiell IG, Sivilotti ML, Bullard MJ, Emond M, Symington C, et al. Sensitivity of computed tomography performed within six hours of onset of headache for diagnosis of subarachnoid haemorrhage: prospective cohort study. BM/ 2011;343:d4277.

8 Gorchynski J, Oman J, Newton T. Interpretation of traumatic lumbar punctures in the setting of possible subarachnoid hemorrhage: who can be safely discharged? Cal J Emerg Med 2007;8:3-7.

9 Page KB, Howell SJ, Smith CML, Dabbs DJW, Malia RG, Porter NR, et al. Bilirubin, ferritin, D-dimers and erythrophages in the cerebrospinal fluid of patients with suspected subarachnoid haemorrhage but negative computed tomography scans. J Clin Pathol 1994;47:989.

10 Heasley DC, Mohamed MA, Yousem DM. Clearing of red blood cells in lumbar puncture does not rule out ruptured aneurysm in patients with suspected subarachnoid hemorrhage but negative head CT findings. Am I Neuroradiol 2005;26:820-4.

11 Buruma OJS, Janson HLF, Den Bergh FAITM, Bots GT. Blood-stained cerebrospinal fluid: traumatic puncture or haemorrhage? J Neurol Neurosurg Psychiatry 1981;44:144-7.

12 Kang DH, Park J, Lee SH, Park SH, Kim YS, Hamm IS. Does nonperimesencephalic type non-aneurysmal subarachnoid hemorrhage have a benign prognosis? J Clin Neurosci 2009;16:904-8.

13 Greebe P, Rinkel GJ. Life expectancy after perimesencephalic subarachnoid hemorrhage. Stroke 2007:38:1222-4.

14 Schwartz TH, Solomon RA. Perimesencephalic nonaneurysmal subarachnoid hemorrhage: review of the literature. Neurosurgery 1996:39:433-40.

15 Perry JJ, Symington C, Mansour M, Taljaard M, Stiell IG. Is this subarachnoid hemorrhage significant? A national survey of neurosurgeons. Can J Neurol Sci 2012;39:638-43.

16 Schull MJ. Lumbar puncture first: an alternative model for the investigation of lone acute sudden headache. Acad Emerg Med 1999;6:131-6.

17 Perry JJ, Stiell IG, Sivilotti ML, Bullard MJ, Lee JS, Eisenhauer M, et al. High risk clinical characteristics for subarachnoid haemorrhage in patients with acute headache: prospective cohort study. BMJ 2010;341:c5204.

18 Perry JJ, Stiell IG, Sivilotti ML, Bullard MJ, Hohl CM, Sutherland J, et al. Clinical decision rules to rule out subarachnoid hemorrhage for acute headache. JAMA 2013;310:1248-55.

19 Vermeulen MJ, Schull MJ. Missed diagnosis of subarachnoid hemorrhage in the emergency department. Stroke 2007;38:1216-21.

20 Leblanc R. The minor leak preceding subarachnoid hemorrhage. J Neurosurg 1987;66:35-9.

21 Vermeulen M, Hasan D, Blijenberg BG, Hijdra A, van Gijn J. Xanthochromia after subarachnoid haemorrhage needs no revisitation. J Neurol Neurosurg Psychiatry 1989;52:826-8.

22 Perry JJ, Sivilotti ML, Stiell IG, Wells GA, Raymond J, Mortensen M, et al. Should spectrophotometry be used to identify xanthochromia in the cerebrospinal fluid of alert patients suspected of having subarachnoid hemorrhage? Stroke 2006; 37:2467-72.

23 Beetham R. Recommendations for CSF analysis in subarachnoid haemorrhage. / Neurol Neurosurg Psychiatry 2004:75:528.

24 Beetham R. CSF spectrophotometry for bilirubin-why and how? Scand J Clin Lab Invest 2009;69:1-7.

25 Edlow JA, Bruner KS, Horowitz GL. Xanthochromia. Arch Pathol Lab Med 2002;126:413-5.

26 Arora S, Swadron SP, Dissanayake V. Evaluating the sensitivity of visual xanthochromia in patients with subarachnoid hemorrhage. J Emerg Med 2010;39:13-6.

27 Dupont SA, Wijdicks EF, Manno EM, Rabinstein AA. Thunderclap headache and normal computed tomographic results: value of cerebrospinal fluid analysis. Mayo Clin Proc 2008:83:1326-31.

28 Chu K, Hann A, Greenslade J, Williams J, Brown A. Spectrophotometry or visual inspection to most reliably detect xanthochromia in subarachnoid hemorrhage: systematic review. Ann Emerg Med 2014;64:256-64.

29 Perry IJ, Spacek A, Forbes M, Wells GA, Mortensen M, Symington C, et al. Is the combination of negative computed tomography result and negative lumbar puncture result sufficient to rule out subarachnoid hemorrhage? Ann Emerg Med 2008;51:707-13.

30 Lang DT, Berberian LB, Lee S, Ault M. Rapid differentiation of subarachnoid hemorrhage from traumatic lumbar puncture using the D-dimer assay. Brief Scientific Reports 1990;93:403-5.

31 Watson ID, Beetham R, Fahie-Wilson MN, Holbrook IB, O'Connell DM. What is the role of cerebrospinal fluid ferritin in the diagnosis of subarachnoid haemorrhage in computed tomography-negative patients? Ann Clin Biochem 2008:45:189-92.

32 Czuczman AD, Thomas LE, Boulanger AB, Peak DA, Senecal EL, Brown DF, et al. Interpreting red blood cells in lumbar puncture distinguishing true subarachnoid hemorrhage from traumatic tap. Acad Emerg Med 2013;20:247-56.

(c) BMJ Publishing Group Ltd 2015

Appendix: Clinical characteristics, examination results, and outcomes of 15 patients with positive SAH with lumbar puncture 